Journal of Jungian Scholarly Studies

Vol. 7, No. 4, 2011

\title{
Reading for Psyche: Numinosity
}

\author{
Inez Martinez, Ph.D.
}

In The Idea of the Holy Rudolph Otto terms being awed when experiencing a visitation of the divine "numinous." Jung and Jungian scholars retain the characteristic of "awesomeness" from Otto's concept of numinosity, ${ }^{1}$ but Jung takes Otto's religious use of the term and psychologizes it, seizing upon it as an explanation of an experience of a power greater than one's will within oneself. $\mathrm{He}$ says, "Numinosity is wholly outside conscious volition" (On the Nature of Psyche; $C W$ 8, par. 383).

For Jung, as Roderick Main points out, experience is the factor that allows a focus on psychology. ${ }^{2}$ Because experience is the basis of theorizing, religion is not a necessary or exclusive framework for exploring the psychological realm of numinous experiences. Imaginative literature is rich with accounts of numinous experiences. Besides offering a wealth of specific instances for reflection and analysis, literature also offers readers possible access to numinous energy through the subjective experience of reading imagined narratives. Crucially, literature functions as a conduit between unconscious and conscious understanding and bridges individual and collective consciousness. Jung addresses these functions of literature when he asserts in "Psychology and Literature" that "creative work arises from unconscious depths" ( $C W 15$, par. 159) and claims in "On the Relation of Analytical Psychology to Poetry" that "just as the one-sidedness of the individual's conscious attitude is corrected by reactions from the unconscious, so art represents a process of self-regulation in the life of nations and epochs" ( $C W 15$, par. 151).

One might explore numinous experiences rendered in literature through a variety of psychological questions, such as their ascribed or implied source (archetypes being one possible answer) or their relevance to the cultural unconsciousness of the times in which they were written or their relevance to the cultural unconsciousness of the times in which they are being read. I wish to focus on the question that inspired Jung, that is, the role of numinous energy in the process of transformation. He was quite aware that the results of numinous experiences need not always be positive. By the time he dictates Memories, Dreams, Reflections, he treats as commonplace the perception that "the numinosum is dangerous because it lures men to extremes ..." (154). Whether a "numinosum" leads to integration of unconscious material or not and of what any integration might consist depends on many factors. Literature, because of its multitude of 
renderings of numinous experiences, has the capacity to manifest complexity concerning successful and unsuccessful attempts at their integration.

Further, literature is an endless source of symbols in narration, and, as Warren Colman points out in his essay on the self, it is the "numinosity of symbols" that allows Jung to claim psychological facticity for psychological experiences (158). In other words, symbols can convey numinous experience, not as scientific evidence, but as phenomenological, subjective reality. Readers of literature have access to this symbolic level of psychological experience.

Thus, because of literature's extensive renderings of numinous experiences in symbolic forms, a focus on numinous moments in a text can yield an everunfolding understanding of the complexity of the factors affecting both positive and negative transformation. The understanding can be ever-unfolding because each generation's experience and context allow literature from previous times to be understood anew. Further, each reader's unique experience and perspective mean previously unrecognized aspects of unconscious manifestation latent in a text may be perceived by the reader capable of grasping it. In sum, reading literature for renderings of numinous experiences can inform generations of readers about causes, effects and factors affecting successful, or partial, or failed processes of integration of unconscious material revealed through numinous experience.

For the purposes not only of identifying but of interpreting numinous experiences in literature, I wish to emphasize the characteristic of revelation in the sense not of divine apparition, but of possibly transformative understanding. Many such moments of revelation are iconic in western literature: in Oedipus Rex, Oedipus's realization that he is the murderer of his father, husband of his mother; in King Lear, Lear's grasping the tragic consequences of his lack of consciousness as he cradles the dead Cordelia in his arms; in Moby Dick, Ahab's feeling himself crucified among the harpoon ropes atop the white whale; in The Awakening, Edna's tearful understanding that sexual fulfillment apart from love is a "cup of life" (83).

To illustrate the wide applicability of reading for psyche through focus on literary renderings of numinosity, I have chosen lesser known tales - a religious, a secular, and a psychological framing of numinous moments. Each literary portrayal, through plot, characterization, and symbol yields specific understanding of the general relationship of numinous experiences to psychological transformation.

Flannery O'Connor's short story, "Revelation," announces by its title that the story concerns a numinous encounter. The word "revelation," while it can be used to refer to our more ordinary insights, is traditionally used to refer to communications from God, and I have selected this story because it is a clear instance of a religious perspective on numinous experience. It is characterized by a profound optimism in the face of profound human unconsciousness. ${ }^{3}$ 


\section{Martinez}

For a revelation to occur, a character must first be in the dark. O'Connor makes her main character's need for enlightenment so obvious as to be funny. ${ }^{4}$ Mrs. Turpin is an overweight, middle-class bigot who considers herself superior to people she refers to as "white trash" and "niggers" (250). She shows herself a snob in the waiting room of a doctor's office through a snooty tiff about hogs she has with a woman she considers "white trash" (252). Mrs. Turpin asserts that her hogs are clean because her husband, Claud, hoses them down every day. The "white trash" woman comments that she would never be caught dead "'scoot[ing] down no hog with no hose"" (252). Both of them clearly believe themselves superior not only to one another but also to hogs.

Mrs. Turpin's confidence in her values appears in her routine musings before sleep. They involve classifying people into a "heap" with "most colored people . . . on the bottom," and "next to them-not above, just away from. . the white trash." Above them come "home-owners" and then "home-and-land owners" like her and Claud. But then above them are people with "bigger houses" and "much more land." The system then breaks down because some of those people are "common" or even "colored." She resolves this paradox by dreaming that "they were all crammed in together in a box car, being ridden off to be put in a gas oven" (250). Unconsciously, Mrs. Turpin is a Nazi willing to exterminate any human beings whose existence disrupts her hierarchical view of people or of herself.

Mrs. Turpin receives a series of revelations in this tale. The first results from her attempt to separate herself from the woman she considers "white trash" by engaging in a conversation with a middle-class woman in the doctor's office. This woman's daughter, Mary Grace, becomes increasingly furious at their mutual selfsatisfaction, as she struggles to read a book entitled Human Development. O'Connor, by naming her Grace, seeks to insure that we readers will not miss her role as divine communicator.

Mrs. Turpin's self-congratulation keeps building until she exclaims, "If it's one thing I am . . . it's grateful. When I think who all I could have been besides myself and what all I got, a little of everything and a good disposition besides, I just feel like shouting, "thank you, Jesus ..." This explosion of gratitude culminates in her first revelation. Mary Grace throws the book of Human Development at her, striking her in the head. She then leaps upon her, grabs her neck, and tries to throttle her. Mrs. Turpin's perspective is radically altered, first perceiving what is happening as far away, then as magnified and close. Meanwhile, she is all the time unable to move. These details suggest being psychologically overwhelmed as in an experience of awe.

One of the factors affecting the possibility of transformation then appears. Mrs. Turpin believes that the girl does know her in some way. Her belief in the 
possibility of revelation opens her to receive one. As Mary Grace is being carried off to an ambulance, Mrs. Turpin asks her, "What you got to say to me?" After "locking" eyes with Mrs. Turpin, Mary Grace whispers, "Go back to hell where you came from, you old wart hog" (259).

Mrs. Turpin is "struck" (259) and becomes increasingly incensed, precisely because she believes that the girl's words are indeed a revelation from God. All day, fuming, she cannot fathom why God would send her, who does all she can for "folks" who cannot be helped (256), who leads a good, religious, middle-class life, such a message, particularly when there are all those "white trash" people around.

Another factor affecting possible transformation, then, can be anger, fury at the contradiction of what one thinks to be true about oneself. Resentment, self-pity, and a sense of unfair victimization are frequently characteristic of numinous revelations about who one is. Think of Oedipus, Lear, Ahab, and, of course, Mrs. Turpin. O'Connor works a theme familiar to readers of the stories of powerful men in a character as ordinary as ourselves. Anger fuels reflecting on the potentially transformative event.

Another emotion evoked by Mary Grace is expressed by a minor character, the mother of the "white trash" woman with whom Mrs. Turpin spars. After Mary Grace is pulled from Mrs. Turpin, she is physically subdued by an inoculation from the doctor. As she, the person in the room who has grasped Mrs. Turpin's inflated state, is literally carried away to an ambulance the "white trash" woman labels her a "lunatic." The woman's mother utters the only words of compassion to appear in the entire story. As she watches Mary Grace being subdued and carted off, she "murmurs": “" po' critter"” (260). Her simple words offer a clue as to how to read the symbolism of the pigs.

Pigs are animals with ancient reputations including having been sacred (Joseph Campbell lists pigs as third in the evolution of sacred beings after the moon and the serpent in Primitive Mythology 197) and being so filthy as to be untouchable and inedible. The story specifically mentions their reputation as being smart enough to be chosen for space exploration (264), a use that ended in a dead pig when the creature was left upright in his astronaut suit for the post-space trip examination. Mrs.Turpin concludes, "naturally a hog should be on all fours" (265). These contradictory valences pose the question of the value of pigs, a question whose answer influences one's interpretation of Mrs. Turpin's penultimate revelation. ${ }^{5}$

O'Connor addresses the question through having Mrs. Turpin take over the hosing of her pigs from her husband. At sunset, as the sun turning an angry red slips behind the tops of the trees, Mrs. Turpin, standing in her pig parlor, unconsciously aims a stream of hose water into the eye of the old sow surrounded by her shoats, an image replicating on a comic level the interplay between herself and her God. Oblivious of her challenge to the sight of her hog, she directs her attention to the opponent whom she feels has insulted her. She challenges God. 


\section{Martinez}

"Why me?" she rumbled.

"... How am I a hog?. ..."

"If you like trash better, go get yourself some trash then. You could have made me trash, or a nigger. . .." She shook her fist with the hose in it. ... (265-66)

The setting sun seems to be responding. O'Connor writes:

In the deepening light everything was taking on a mysterious hue. The pasture was growing a peculiar glassy green. . . . $[\mathrm{Mrs}$. Turpin] braced herself for a final assault and this time her voice rolled out over the pasture. "Go on," she yelled, "call me a hog! Call me a hog again. From hell. . .." (266)

The transformative moment of revelation is about to be born of the very intransigence of Mrs. Turpin's unconsciousness - and of nature's representing God. The text reads: A final surge of fury shook her and she roared, "'Who do you think you are?"” (266)

Mrs. Turpin's faith, the faith that led her to accept Mary Grace's communication as a divine revelation, is then rewarded.

The color of everything, field and crimson sky, burned for a moment with a transparent intensity. The question carried over the pasture ... and returned to her clearly like an answer from beyond the wood. (266)

As her question to God echoes back to her as God's reply, "Who do you think you are?" Mrs. Turpin gazes, "as if through the very heart of mystery . . . at the hogs. A red glow suffused them. They appeared to pant with a secret life" (266). Gazing through "the very heart of mystery" describes a moment of awe and revelation.

A clue to an aspect of the meaning of this mystery is the compassionate response of the old woman who saw Mary Grace being carted off and murmured, "'Po critter" (260). The reader, who typically has shared Mrs. Turpin's assumption of superiority to hogs, is challenged to grasp with Mrs. Turpin that the hogs are God's creatures even as is she, even as are the "white trash" and "niggers," and it is this fact that makes them all equal in value, thus dissolving the hierarchy upon which she based her self-esteem. Yet another hierarchy immediately appears. Mrs. Turpin's final revelation is a vision of a streak of lit sky functioning as a bridge across which the saved are marching, singing and dancing into heaven, the parade led by "white trash" and "niggers," with the rear consisting of people like herself and Claud, marching with "dignity," and having their "virtues burned away" (267). As critic Margaret B. McDowell has noted, for O'Connor, it is not so much sins, but virtues that must be sacrificed. 
O'Connor is breathtakingly optimistic in her rendering of the salvation of a sinner as banal and unconscious as Mrs. Turpin. The process of Mrs. Turpin's realizing that she is on a par with her hogs is graced by moments of numinous experience. This story with its clear religious theme treats numinosity with as little ambiguity as it is ever likely to be treated. In fact, I suggest that religiously motivated stories typically are characterized by optimism in their rendering of numinosity. Further, this story offers a model for turning a numinous experience into a transformative one when the ego involved is inflated. It implies that for a numinous experience to take place, there must first of all be grace, and the appearance of this grace may violate stereotypical ideas. It may appear in the guise of violence, apparent lunacy, and/or a shocking kind of mirroring. For the experience to have its salutary effects, the ego must be wounded, must have faith that the wound means something, must pursue that meaning, and must risk utter absurdity in claiming its point of view in order to realize the absurdity of that point of view. And, as with many numinous experiences, the disconnect between beings will then diminish, and a new understanding of one's relatedness to other beings will emerge.

While O'Connor does not follow Mrs. Turpin into the next day to show her changed character, the fact that her vision of salvation reverses her hierarchy, that is, includes her as the least of the saved, is demonstration enough that her selfunderstanding has been fundamentally transformed.

Unlike O'Connor's “Revelation,” E. M. Forster's story, "The Road from Colonus," portrays a numinous experience that fails to catalyze transformation. Further, that failure leads to personality degeneration. This capacity of the numinous to result in negative consequences is in accord with Jung's insistence on the bipolar possibilities of all psychic reality. In The Psychology of the Transference, he writes that the psychological view is not dominated by a moral, but by an observational perspective that admits the imperfect and mixed character of human experience. He suggests that instead of measuring "the vicissitudes of the world's history by the standards of right and wrong, true and false, good and evil," the psychological view prefers "to see the retrograde step in every advance, the evil in every good, the error in every truth . . " ( $C W 5$, par. 442). It follows that in numinous experiences, there lies the opportunity both for personality growth and for personality decay.

Forster's is a secular tale about a $20^{\text {th }}$-century Englishman aging in a culture that, in contrast to Colonus of Ancient Greece, was empty of faith in a divine realm. Unlike Mrs. Turpin, the main character of "The Road from Colonus," Mr. Lucas, is not inflated. Rather, he is depressed. Mr. Lucas is aging and does not like it. Accompanied by his daughter, her fiancé, and some friends, he is fulfilling a youthful dream by visiting Greece. To his disappointment, he is finding Athens "dusty," "Dephi wet," and "Thermopylae flat" (528). He longs to experience life as 


\section{Martinez}

he had in youth and desires to "possess" Greece so that "[1]eaves shall be green again, water shall be sweet, and sky shall be blue" (528).

The meanings of this tale depend on the allusion to Sophocles's Oedipus at Colonus in which the dying Oedipus is taken up by the goddesses, the Erinyes. The party traveling with Mr. Lucas likens him to Oedipus and his daughter to Antigone. These allusions arouse readers' expectations of, and doubt as to whether, Mr. Lucas will meet a death made marvelous by divine intervention because, as critic John V. Hagopian has pointed out, Forster's substituting "from" Colonus for Sophocles's "at" makes the implied comparison between the deaths of Oedipus and Mr. Lucas ambiguous (209).

Mr. Lucas runs ahead of his party to a magnificent grove of plane trees where the party is to lunch. Nearby is a small country inn or "khan." He notices running water and discovers that a stream is flowing from the heart of a huge, hollowed-out plane tree. Acting on his desire to "possess" Greece, he jumps onto a rock within and experiences the stream flowing from the heart of the tree into the world. Suddenly he feels life's joy and a euphoric sense of fulfillment. He delights in the voices of children playing nearby and in the song of a young man. The leaves are green, the sky is blue, and when he tastes the water, it is sweet.

Filled with a sense of imminent completion, he leans back against the tree, closes his eyes, and has "the feeling of the swimmer, who, after long struggling with chopping seas, finds that after all the tide will sweep him to his goal" (529), a goal the reader, taking a hint from the story's title, suspects is death. He is "conscious only of the stream below his feet, and that all things were a stream, in which he was moving" (529). This sense of all things being connected within the flow of the stream leads to a sudden revelation that "something unimagined, indefinable, had passed over all things, and made them intelligible and good." Awed and full of gratitude, Mr. Lucas has the desire to add to the votive offerings hung in the tree by previous grateful visitors, "tiny arms and legs and eyes in tin, grotesque models of the brain or the heart - all tokens of some recovery of strength or wisdom or love." He wants to add the image of an "entire man" (529).

Jung points out that the "in the world of images," the tree of life is also the tree of death, a coffin. He cites the use of hanging images in trees as effigies and notes the symbolic implications of death as rebirth. (Symbols of Transformation, CW 5, par. 349). Mr. Lucas's numinous experience in the plane tree promises at least a transcendent quality to his imminent death, a quality issuing from the sudden sense of his personal wholeness and of the connectedness of all beings.

$\mathrm{He}$ is, however, unable to communicate his profound experience or his feelings to the party traveling with him when they arrive. He is repelled by the shallowness of their responses to the place, and when, in the gaiety of their conversation his 
daughter, Ethel, suggests staying at the country inn, not just for a night, but for a week, he is inwardly thrilled. Being in their company has warned him that he may lose the vision he has had if he does not stay at the place a while and confirm it. He attempts within the limits of his ability to communicate his insistence on remaining at the khan. His daughter, appalled at the unhygienic condition of the khan and its inhabitants, finally prevails upon her fiancé to force her father onto his mule and is persuaded that they have thus saved him. At an opening in the hills that allows a brief view of the plane trees below, Mr. Lucas allows "the reins to fall from his hands."

This last image, the reins falling from Mr. Lucas's hands, implies one way that the promise of a positive numinous experience may not be realized. The infusion of psychic energy in the individual is not enough. Individual openness to the experience is not enough. A society that does not acknowledge or value numinous experiences can snuff out the flame. An individual overcome by societal collective unconsciousness is rendered incapable of keeping hold of the reins, of acting on the new consciousness, thereby wasting and losing the psychic energy of the numinous experience.

Forster ruthlessly portrays the impact of living in such a psychologically superficial society through detailing the degeneration of Mr. Lucas as a human being. The story is divided into two parts, and Part II portrays Mr. Lucas as a querulous old man on the brink of being consigned by his daughter, Ethel, who is about to marry her fiancé, to the care of his sister whom he hates and fears. Over breakfast, he complains to his daughter of anything that suggests life: running water, the cries of children, the singing of a young man. In the midst of his rant, a package arrives from a friend in Greece in which a gift is wrapped in an old newspaper. Ethel reads in that scrap of paper how an ancient plane tree fell on a khan the night of their visit to the place, killing all within. Ethel is moved by how close her father came to death and credits Providence with his survival. Of course, viewing Mr. Lucas's physical survival as providential, in light of his enduring a living death, is an irony that poor Mr. Lucas, totally lacking self-knowledge, cannot grasp.

Mr. Lucas misses his meaningful death. His numinous experience, which presaged dying while in a state of feeling whole in himself and connected with all reality, leads not even to regret at its loss. Once he has dropped the reins, he cannot engage with his numinous experience through reflection, communication, or action. Mr. Lucas's inability to bring consciousness to his experience is reflective of his culture. Lucy Huskinson in "Holy, Holy, Holy: the misappropriation of the numinous in Jung" argues that for a numinous experience to be transformative, rationality must be brought to the irrational experience (210). But how was Mr. Lucas to do that when his world valued not even the categories of numinous and visionary experiences, and his language had no means to convey such realms? 


\section{Martinez}

Unlike Mrs. Turpin, a bigot saved by faith in divine revelation, Mr. Lucas is an old man living in a time when passing from one state to another is symbolized by tourism, not transformation. His story illustrates not only that a numinous experience by itself need not result in transformation, but also that the cultural context in which it occurs helps determine whether it can be integrated.

I wish to suggest that stories dealing with numinous experiences, unless they are consciously religious, such as O'Connor's "Revelation," typically pose them as ambiguous in their immediate aftermath and difficult to integrate. As Jung says, they "can be healing or destructive ..." (On the Nature of Psyche, CW 8, par. 405).

Let me illustrate by citing the contradictory results of numinous experiences for two characters from Haruki Murakami's profoundly psychological novel, The Wind-Up Bird Chronicle. In this book, psyche exists as a realm that can be visited. It is a realm shared by persons living and dead. Most importantly, it is a realm where experiences not integrated by individual characters during life may, through the psyche of a living character, become transformed. In other words, one character - whose identity has been mysteriously linked with those of others, may through his transformative work in the realm of psyche, bring to fruition the promise of the numinous experiences of those others who were themselves paralyzed by them. Specifically, the main character, Toru Okada, in his heroic journey to find and bring home his wife who has been psychically captured by the irrational powers of her brother, is able in the realm of psyche to bring to fruition the numinous experiences of many characters. I will focus on two of those characters to illustrate.

One is a veterinarian in Japan-occupied China during World War II who lived long before Toru. Through the imagination of his grandson, Cinnamon, this veterinarian witnesses a military execution performed with a baseball bat and is then suddenly yanked into a pre-dug grave by the falling victim. He never escapes a sense that he is helpless against fate. He is linked to Toru through the symbol of the bat, a weapon Toru uses in a passion to bloodily beat a man - and through a distinctive blue mark on his face, a mark that Toru finds inscribed on his face when he awakens from one of his visits to the realm of irrational psyche.

Another is a Lieutenant who witnesses a fellow officer skinned alive for information he does not have. The analyst and literary critic Toshio Kawai has claimed that this horrendous passage illustrates how numinosity has become meaningless, nonsymbolic violence, pure "negation" (196). His response is understandable if one evaluates the Lieutenant's experience solely in terms of his individual life, but the novel links the Lieutenant's life with Toru's. 
First, both are linked through their each having profound experiences while in the bottom of drywells. Murakami places Toru in a drywell for many days. It becomes the medium through which Toru reaches the realm of psyche, thus connecting Toru's journey with the Lieutenant's numinous moments. The Lieutenant, after witnessing the horrific flaying, is tossed naked into the darkness of a drywell in the Mongolian desert. There, he is blinded for a few seconds each day as the sun passes over his well. In his first description of this overwhelming experience he describes his awe as so profound that it leads to a sense that he should die. He says, "If it could have happened in the bliss of this marvelous light, even death would have been no threat. Indeed, I felt I wanted to die. I had a marvelous sense of oneness, an overwhelming sense of unity. . . . [T] he true meaning of life resided in that light that lasted for however many seconds it was, and I felt I ought to die then and there" (166).

In a sense, he does die. Commenting on his experience, he says, "I feel as if, in the intense light that shone for a mere ten or fifteen seconds a day in the bottom of the well, I burned up the very core of my life, until there was nothing left. . . [N]o matter what I have encountered, no matter what I have experienced since then, I ceased to feel anything in the bottom of my heart. . . That was the time for me to die" (170). Failing that, he has lived, again in his words, as a "hollow, empty shell" (209).

This hollowness leads to the second way he is linked to Toru. Because of his hollowness, when given the opportunity to kill and stop the sadistic violence of the man who skinned his fellow officer alive, the Lieutenant is unable to do so. In terms of his time-and-space-bound life, his numinous experience leads to relational and moral impotence. Toru's eventual encounter with his evil antagonist through the help of the Lieutenant as "the hollow man" parallels the Lieutenant's opportunity to act against known evil.

Third, his life becomes linked to Toru's through the horrific flaying. Murakami creates this link through one of Toru's dreams. In response to his having beaten the man with a bat, Toru dreams that the man's skin crawls off his body toward him and drapes itself upon him. This guilt-expressive image links the victim of the flaying that the Lieutenant witnesses and the victim Toru beats with the bat, thus confounding any reader response that Toru is simply "good." Whereas the Lieutenant merely witnesses human irrational violence, Toru participates in and is thus able to confront it.

Toru's efforts in the realm of psyche carry the life experiences of both the veterinarian and the Lieutenant, each of whom had been paralyzed by his respective numinous experience. When Toru finally does slip through the well wall into the realm of psyche, it is the "hollow man," a phrase echoing the selfdefinition of the Lieutenant, who is his ally and who helps him reach the room in the unconscious where his wife is trapped. There, in the realm of psyche, 


\section{Martinez}

mysteriously finding a bat, he does battle with her brother, the personified force of evil, and wins. Overcoming him there is the opposite of the veterinarian's passive submission to fate; further, it is the completion of the Lieutenant's task of killing the sadistic man-skinner. Through their psychic connections with Toru, the veterinarian is no longer the pawn of fate, and the Lieutenant is no longer impotent against evil or in life. In fact, through a later dream of Toru's, the Lieutenant helps father a child and gets to live with that child and its mother in the realm of unconscious psyche. Transformation of the veterinarian is suggested in the disappearance of the blue mark from Toru's face.

Murakami portrays psychological integration and transformation as processes independent of time and not limited to individual lifetimes or experiences. Integration of numinous experiences and transformation becomes not just individual, but related processes among human beings. This vision removes the center of meaning from the individual ego and psyche and allows for many possible human centers across time and space. From such a vision, even numinous experiences like Mr. Lucas's that fail to transform an individual have energy that may be realized by another person connected on the level of psyche. Perhaps some readers of Mr. Lucas's failure to integrate the life and death of his vision have used their reading transformatively. That the portrayal of the numinous in literature has that possibility is more easily entertained, I think, than Murkami's more radical portrayal of human beings sharing identities and transformations with one another in the realm of psyche.

Nevertheless, Murakami's vision is imaginatively compelling. If psyche is truly shared, why should such fruitions not be possible? Murakami's novel invites us to imagine that in the realm of psyche, change is possible not only for the dead through the living, but for still living persons, such as Toru's wife, through the engagement of other living persons, such as Toru, with psychological forces. Such a vision is bravely optimistic about the potential power for effecting collective change through individual psychological work.

Death in these three stories is a context for numinous experiences and for whether integration occurs. Mrs. Turpin undergoes the death of her ideal self-image and grasps her existence as a creature redeemed not by her virtues but by the revelations from her creator. The plot leads to the idea that partial ego death is a necessary part of personal transformation. Mr. Lucas fails to follow his numinous understanding to a meaningful death and instead endures a living psychological death. This plot suggests that death experienced as living cut off from the unconscious psyche is a tomb where transformation is no longer possible. The veterinarian pulled into the grave, believing himself doomed by fate, through Toru has his narrative transformed into acting against and triumphing over evil. The 
Lieutenant, who died emotionally after his experience of the light from the bottom of the drywall and who was unable to act against the man who flayed his comrade, through Toru is able to slay the agent of evil, help father a child, and live a relationship with the child's mother. These characterizations portray psychological deaths following numinous encounters being transformed through the imaginal life of another.

The conceptual abstractions about numinosity I've drawn from O'Connor's and Forster's stories are not unknown in the world of psychological theory, so the question could be raised as to why reading a psychological theoretical text is not sufficient. What does reading literature contribute to understanding of psychological life? Unfortunately, the experience of having a concept that does not result in personal transformation is all too common. Literature differs from theory in that it potentially communicates not simply concepts, but sensuous and emotional understanding of the elements of a story. Senses stimulate emotions. Emotions indicate that channels from the unconscious psyche have been opened. When reading a story combines emotional openness and conceptual understanding - even if the concept is new or threatening to the reader - then the concept is accompanied by unconscious energy making psychological movement in the reader possible. To put it another way, when one reads theory, one is operating conceptually and looking rationally for proof. When one reads fiction, one is exposed to experience of unconscious psyche being revealed through imagination in a sense and emotion-stimulating narrative. This latter kind of communication potentially releases energy and can lead to conscious reflection upon and interpretation of previously unconscious materials.

There also exist psychological revelations in literature not yet in psychological theory. Murakami's vision, to my knowledge, is not articulated in psychological theory. His portrayal of numinosity and transformation not only offers the transformative power of story; it offers a new way to think of integration and transformation as psychically shared. ${ }^{7}$ Thus another reason to read literature for psychological understanding is that it can, as Sophocles's Oedipus story did for Freud and Goethe's Faust story did for Jung, offer perspectives on psyche not previously available in psychological theory.

Jung's appropriation of the idea of numinosity for understanding psyche provides a fertile approach to reading literature for understanding psyche. Literature abounds with portrayals of moments when the ego is awed in the sense of overwhelmed, moments ripe with possible revelation. Reading so as to understand the psychological implications of those moments potentially enriches our understanding of psyche, and, in particular, of transformation. 


\section{Martinez}

\section{Endnotes}

${ }^{1}$ See, for example, Ann Casement's statement, "activat[ing] opposing archetypal contents in the collective unconscious .... results in numinous or awesome experiences" (101). Or as Mary Ann Matoon states: "Many cultures and individuals experience archetypal dreams as especially numinous (awe-inspiring)" (249).

${ }^{2}$ Discussing Jung's orientation with regard to religion, Main says, "The emphasis on direct religious experience is ... a prioritising of the psychological dimension. ..." (308).

${ }^{3} \mathrm{O}^{\prime}$ Connor's conscious resistance to Jung's psychologizing of religious experience, as noted by early critics such as David E. Matchen and Wilton Beauchamp (5), need not prevent reading her work for what it reveals about the impact of numinous experience on psychic transformation. What is revelatory about psyche in literature is not dependent upon the author's conscious intention or ideology but upon the author's conveying in her work images and narratives emerging from collective unconsciousness through her consciousness.

${ }^{4}$ Critic Frederick P.W. McDowell claims that in "Revelation," “O'Connor's comic mastery reaches its apogee. .." (1004).

${ }^{5}$ Rebecca K. Rowley in "Individuation and Religious Experience: A Jungian Approach to O'Connor's 'Revelation'" offers a reading of "Revelation" as if it were a specimen in which various of Jung's ideas can be found, among them his ascription of psychological meaning to symbol. This article demonstrates a method of reading literature not for psyche, but for explication of literature in terms provided by Jung. This kind of reading, conceptually intent on finding representations of Jung's ideas in a fiction, can fail to be sensitive to the details that guide an exploration of psyche. Rather than looking for ways that "Revelation" creates suggestions for understanding the pig symbolism, for example, Rowley cites a dictionary of symbols in order to claim that "pigs represent 'impure desires, the transmutation of the higher into the lower and the amoral plunge into corruption'" (Cirlot $149 \mathrm{ctd}$. 98). This kind of arbitrary assigning of meaning to symbols misses those details that ground suggestions of meaning in the text and, in this case of the pigs, leads Rowley to ascribe a meaning the opposite of the one implied through the words of the old woman. This character's compassionately introducing creaturehood into the narrative prepares for Mrs. Turpin's revelation when peering into the "mystery" of the pigs (266). Instructively, Rowley's mechanical method of imposing Jungian concepts on the story is a telling example of how reading literature with Jung's concepts in mind need not focus on discovering aspects of psyche. To read literature for psyche, Jung's concepts, such as psychologizing numinous experience, can be gateways into discovering what literature can reveal about psyche, but only if literature is understood as a primary source for understanding. 


\footnotetext{
${ }^{6}$ Here O'Connor is literalizing the luminosity of numinous revelations. Jung has noted this characteristic of numinosity. In On the Nature of Psyche, he says, "numinosity entails luminosity" (CW 8, par. 101).

${ }^{7}$ The experience of analysis through transference and counter-transference can be seen as a process in which integration of unconscious materials is shared. Murakami's vision, however, suggests that shared integration can occur between individuals who have never even met; further, that it can occur between individuals only one of whom still lives.
}

\section{Works Cited}

Campbell, Joseph. Primitive Mythology: The Masks of God. 1959. New York: Penguin, 1985. Print.

Casement, Ann and David Tacey, ed. The Idea of the Numinous: Contemporary Jungian and Psychoanalytic Perspectives. New York: Routledge, 2006. Print. --- "The shadow." Papadopoulos. 94-112. Print.

Chopin, Kate. The Awakening. 1899. New York: Norton, 1976. Print.

Cirlot, J.E. A Dictionary of Symbols. Trans. Jack Sage. New York: Philosophical Library, 1971. Print.

Colman, Warren. "The self." Papadopoulos. 2006. 153-74. Print.

Forster, E. M. "The Road from Colonus." The Norton Anthology of Short Fiction. $2^{\text {nd }}$ ed. Ed. R. V. Cassill. New York: Norton, 1981. Print.

Hagopian, John V. "The Eternal Moments in the Short Fiction of E. M. Forster." College English 27.3 (1965): 209-15. Rpt. in Short Story Criticism. Ed. Anna J. Sheets. Vol. 27. Detroit: Gale Research, 1998. Literature Resource Center. Web 15 Dec. 2011.

Huskinson, Lucy. "Holy, Holy, Holy: the misappropriation of the numinous in Jung. Casement and Tacey. 200-12. Print.

Jung, Carl G. Memories, Dreams, Reflections. 1961. Trans. Richard and

Clara Winston. Ed. Aniela Jaffé. Rev. ed. New York: Vintage, 1965. Print.

- - -. The Collected Works of C. G. Jung. Ed. Sir Herbert Read et al. Trans. R. F. C. Hull. $2^{\text {nd }}$ ed. Princeton: Princeton UP, 1953-79. 20 vols. Bollingen Series 20. Print.

Kawai, Toshio. "The experience of the numinous today: from the novels of Haruki

Murakami." Casement and Tacey. 186-99. Print.

Main, Roderick. "Religion." Papadopoulos. 296-323. Print.

Matchen, David E. and Wilton Beauchamp. "Enoch Emery: Flannery O'Connor and Jungian Psychology.” Publications of the Mississippi Philological Association 1 (1982): 1-7. Print.

Matoon, Mary Ann. "Dreams." Papadopoulos. 244-59. Print.

McDowell, Frederick P. W. "Toward the Luminous and the Numinous: The Art of

Flannery O'Connor.” Southern Review 9 (1973): 998-1013. Print.

McDowell, Margaret B. “"Revelation': Overview.” Reference Guide to Short Fiction. Ed.

Noelle Watson. Detroit: St. James, 1994. Literature Resource Center. Web. 15 Dec. 2011.

Melville, Herman. Moby Dick or The Whale. 1851. Ed. Charles Feidelson, Jr. New York: Bobbs-Merrill, 1964. Print.

Murakami, Haruki. The Wind-Up Bird Chronicle. New York: Vintage, 1997. Print.

O'Connor, Flannery. "Revelation." Women and Fiction. Ed. Susan Cahill. New York: Mentor, 1975. 246-67. Print.

Otto, Rudolf. The Idea of the Holy. 1923. Trans. John W. Harvey. New York: Galaxy, 1958. Print.

Rowley, Rebecca. "Individuation and Religious Experience: A Jungian Approach to

O'Connor's “Revelation.” Southern Literary Journal 25.2 (1993)): 92-102. Print.

Shakespeare, William. King Lear. 1623. Ed. Alfred Harbage. New York: Penguin, 1958. Print. 


\section{Martinez}

Sophocles. "Oedipus at Colonus." The Oedipus Cycle, An English Version: Oedipus Rex, Oedipus at Colonus, Antigone. Ed. Dudley Fitts and Robert Fitzgerald.

Trans. Robert Fitzgerald. New York: Harvest, 1939. Print. 